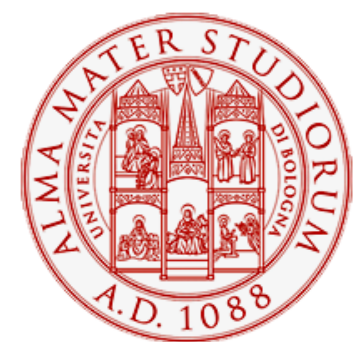

Alma Mater Studiorum - Università di Bologna DEPARTMENT OF ECONOMICS

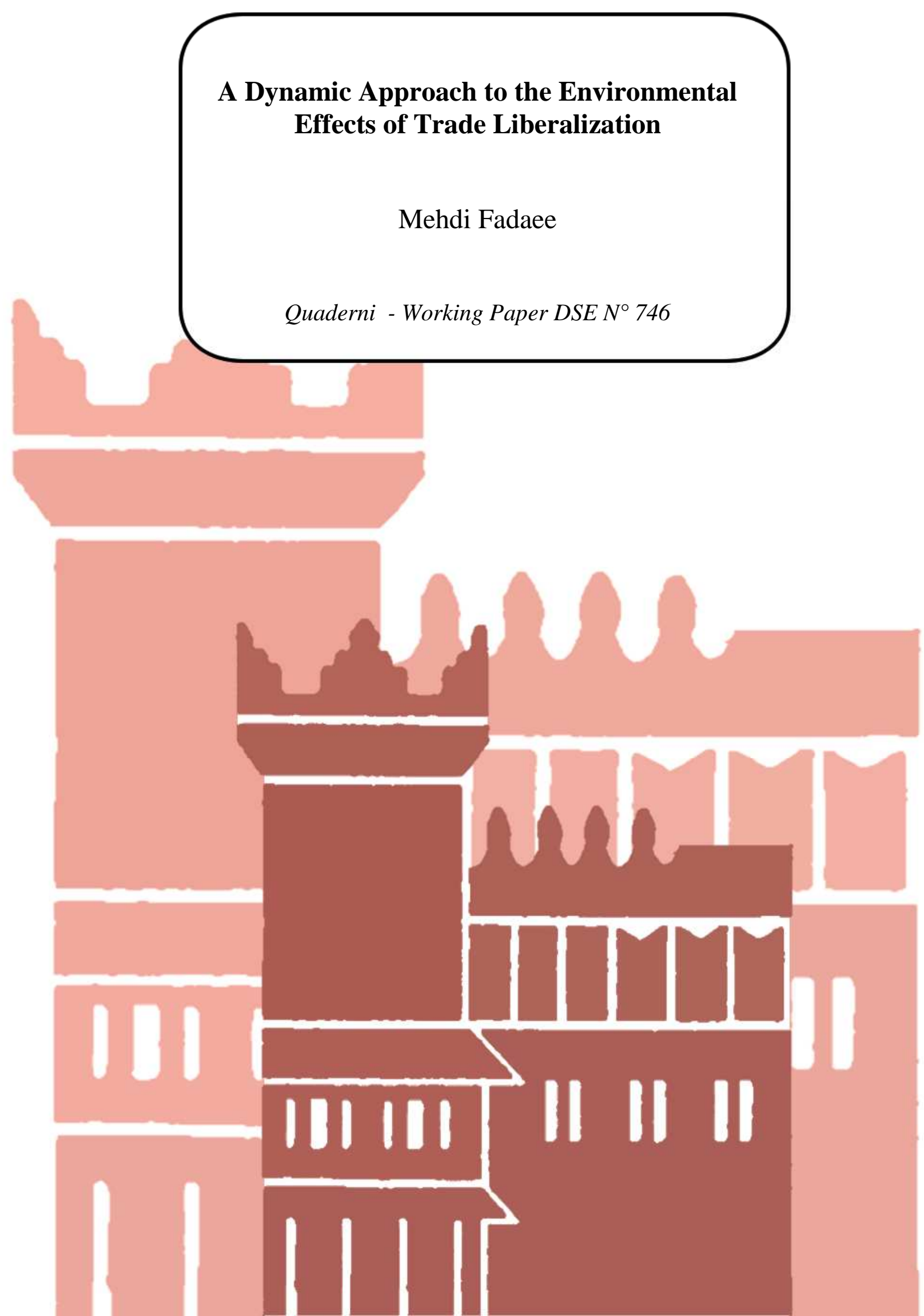




\title{
A Dynamic Approach to the Environmental Effects of Trade Liberalization*
}

\author{
Mehdi Fadaee \\ Department of Economics, University of Bologna \\ Strada Maggiore 45, 40125 Bologna, Italy \\ mehdi.fadaee2@unibo.it
}

December 2010

\begin{abstract}
In this paper, we develop a two-country world differential game model with a polluting firm in each country where there is transportation cost to investigate the equilibrium of the game between firms when they decide to trade or not and to see under which conditions social welfare coincides with the market equilibrium. We find out that in the static game bilateral trade is always the equilibrium for any acceptable transportation cost while in the dynamic game social planner can prevent the inefficient outcome by imposing and determining the proper amount of Pigouvian taxation.

Keywords: Environmental pollution, International trade, Differential game, Openloop strategy, Feedback strategy

JEL Classification: C73, F18, H23, Q56
\end{abstract}

${ }^{*}$ I would like to thank Luca Lambertini for his helpful comments and advice throughout this study. I also wish to thank the audience at ASSET meeting, EUNIP conference, ACDD, EBIM workshop and $\mathrm{PhD}$ forum at university of Bologna for their useful comments. 


\section{Introduction}

Controlling the emission of environment-damaging pollution caused by increased economic activity has received a considerable attention in the field of environmental economics. Given that the pollution function is increasing in the output of the industry, we have the usual trade-off between the price effect and the negative externality. If we restrict the output the environment is cleaner but the price is higher.

International trade is playing an important role in expanding global economic activities and there is an increasing amount of literature regarding trade and the environment in trade theory ${ }^{1}$. However, there are not too many contributions regarding the effects of trade liberalization in a dynamic context. What creates negative externality is the stock of pollution not just the current emission of pollution. Thus, we need a dynamic model to study the environmental effect of trade liberalization due to the fact that pollution is accumulated over time. Fujiwara (2009) investigates the effects of free trade on global stock of pollution using a two country differential game model. We develop a two-country world differential game model, where there is a polluting firm in each country, to derive the open-loop and feedback equilibria of the game between firms in case of autarchy, unilateral and bilateral trade when there is transportation cost and also a Pigouvian tax is introduced to reduce damaging emissions.

Most of the existing contributions in the field of environmental economics examine the existence of Pigouvian taxation aimed at inducing firms to reduce damaging emissions directly $^{2}$ or indirectly ${ }^{3}$. Accordingly, the common approach to deal with this problem in all of these studies is to derive the first best, where a social planner chooses a welfare maximizing production plan, and introduce corrective taxes to induce profit-seeking firms to produce at socially optimum level. In our study, the game between social planners is not technically solvable. As a result, it is not possible to outline the social optimum. However, we figure out the market equilibrium and determine which one of the three cases of bilateral trade, unilateral trade or autarchy is the equilibrium of the game between two firms according to the transportation cost and Pigouvian tax quantity. Then, we

\footnotetext{
${ }^{1}$ See Copeland and Taylor (2003), Antweiler et al. (2001), inter alia.

${ }^{2}$ See Bergstrom et al. (1981), Karp and Livernois (1992, 1994), Benchekroun and Long $(1998,2002)$ and Tsur and Zemel (2008).

${ }^{3}$ To this regard, see Downing and White (1986), Milliman and Prince (1989), Damania (1996), Chiou and $\mathrm{Hu}$ (2001) and Tsur and Zemel (2002), Dragone et al. (2009).
} 
determine the extent of tax amount for various quantities of negative externality to which social welfare coincides with market equilibrium.

The remainder of the paper is structured as follows. Section 2 constructs a basic model. Section 3 briefly outlines the static version of the game. In section 4 , the differential game is illustrated and the open-loop and feedback equilibria under autarchy, unilateral and bilateral trade are characterized. Profits and social welfares are assessed in section 5 . Section 6 concludes the paper.

\section{The Setup}

There are two similar countries, indexed by $i=1,2$. In each country there is a firm which produces a single output. Firms supply a homogenous good and their productions, $q_{i}$, have two parts:

$$
q_{i}=q_{i i}+q_{i j}, \quad i, j=1,2 \text { and } j \neq i,
$$

where $q_{i i}$ and $q_{i j}$ denote the amounts of output produced by firm $i$ and consumes in domestic market and is exported to the other country, respectively. It is obvious that the second part becomes zero if there isn't any export.

Exporting firm must pay an iceberg transportation cost which depends on the amount of export. In our setting, $m \in(0,1]$ captures the effect of transportation cost. If there is no transportation cost, $m$ is equal to one. Therefore, the inverse demand function in each country is

$$
p_{i}=a-\left(q_{i i}+m q_{j i}\right), \quad i, j=1,2 \text { and } j \neq i,
$$

where $q_{j i}$ is the amount of goods which is exported by the firm $j$ into country $i$.

Technology is the same for both firms and production takes place at constant returns to scale (CRS), with a constant marginal cost $c$. It is summarized by the cost function $C_{i}=c q_{i}(t)$. Hence, firm $i$ 's instantaneous profits are

$$
\pi_{i}(t)=p_{i}(t) q_{i i}(t)+p_{j}(t)\left(m q_{i j}(t)\right)-c q_{i}(t) .
$$

The production of the final output creates a negative externality in the form of polluting emissions' flow $E(t)=Q(t)$, which increases the stock of pollution, $Z$. Pollution is accumulated over time and is transboundary. The accumulation process of the world pollutant 
follows:

$$
\dot{Z}(t)=\sum_{i=1}^{2} q_{i}(t)-k Z(t), \quad k>0,
$$

where $k$ is the natural purification rate of the pollutant.

The stock of pollution lowers the consumer surplus by the following rule:

$$
C S_{i}(t)=\frac{\left(q_{i i}(t)+m q_{j i}(t)\right)^{2}}{2}-h \frac{Z(t)^{2}}{2}, \quad h>0,
$$

where $h$ measures the effect of negative externality on consumers. However, the instantaneous social welfare in each country is the aggregate amount of firm's profits and consumer surplus:

$$
S W_{i}(t)=\pi_{i}(t)+C S_{i}(t) .
$$

By knowing this setting, we are deriving firms' profit equilibria in autarchy, unilateral and bilateral trade. We will compare these profits as well as social welfares to obtain the trade strategy from the viewpoints of the both, the social planner and the firms.

\section{The Static Problem}

As a preliminary step, in this section, we consider the static Cournot game in order to examine the case where firms maximize their profit functions without taking into account the negative externality because of the lack of corrective tax. We consider the game in figure 1 in which firms make their trade strategy decision, where $\pi_{i}^{A}, \pi_{i}^{T}\left(\pi_{i}^{N T}\right)$ and $\pi_{i}^{B T}$ denote the optimal profit of firm $i$ in the case of autarchy, trade (not trade) in unilateral

\begin{tabular}{|c|c|c|}
\hline \multirow{3}{*}{$\begin{array}{lr} & \text { NT } \\
& \\
& \end{array}$} & NT & $\mathrm{T}$ \\
\hline & $\left(\pi_{1}^{A}, \pi_{2}^{A}\right)$ & $\left(\pi_{1} N T, \pi_{2}{ }^{I}\right)$ \\
\hline & $\left(\pi_{1}{ }^{T}, \pi_{2} N T\right)$ & $\left(\pi_{1} B T, \pi_{2} B T\right)$ \\
\hline
\end{tabular}
and bilateral trade, respectively.

firm 2

Figure 1: The game between two firms when they decide to trade (T) or not (NT).

In autarchy case, there is no trade between the two countries and each firm is monopolist in its own country with the optimal quantity level of $(a-c) / 2$. In the unilateral and 
bilateral trade where firms play under Cournot competition, the equilibrium amount of outputs is summarized in lemma 1 and 2 .

Lemma 1 The equilibrium amounts of firms' output in unilateral trade under (static) Cournot competition are

$$
\begin{gathered}
q_{i i}^{T}=\frac{a-c}{2}, \quad q_{i j}^{T}=\frac{(a+c) m-2 c}{3 m^{2}}, \\
q_{j j}^{N T}=\frac{(a-2 c) m+c}{3 m} .
\end{gathered}
$$

Proof. The maximization problem of trading and not trading firms are

$$
\begin{gathered}
\pi_{i}^{T}=\max _{q_{i i}, q_{i j}}\left(a-q_{i i}\right) q_{i i}+\left(a-q_{j j}-m q_{i j}\right)\left(m q_{i j}\right)-c\left(q_{i i}+q_{i j}\right), \\
\pi_{j}^{N T}=\max _{q_{j j}}\left(a-q_{j j}-m q_{i j}\right) q_{j j}-c q_{j j},
\end{gathered}
$$

with the following necessary conditions (FOCs):

$$
\begin{gathered}
\frac{\partial \pi_{i}^{T}}{\partial q_{i i}}=a-2 q_{i i}-c=0 \\
\frac{\partial \pi_{i}^{T}}{\partial q_{i j}}=a m-m q_{j j}-2 m^{2} q_{i j}-c=0 \\
\frac{\partial \pi_{i}^{N T}}{\partial q_{j j}}=a-2 q_{j j}-m q_{i j}-c=0
\end{gathered}
$$

Consequently, the resulting levels of individual output are

$$
q_{i i}^{T}=\frac{a-c}{2}, \quad q_{i j}^{T}=\frac{(a+c) m-2 c}{3 m^{2}}, \quad q_{j j}^{N T}=\frac{(a-2 c) m+c}{3 m} .
$$

Lemma 2 The equilibrium amounts of firms' output in bilateral trade under (static) Cournot competition are

$$
q_{i i}^{B T}=\frac{(a-2 c) m+c}{3 m}, \quad q_{i j}^{B T}=\frac{(a+c) m-2 c}{3 m^{2}} .
$$

Proof. The maximization problem of firms in case of bilateral trade, which is the same for both because of symmetry, would be

$$
\pi_{i}^{B T}=\max _{q_{i i}, q_{i j}}\left(a-q_{i i}-m q_{j i}\right) q_{i i}+\left(a-q_{j j}-m q_{i j}\right)\left(m q_{i j}\right)-c\left(q_{i i}+q_{i j}\right) .
$$


The first order conditions of this problem w.r.t. controls are

$$
\begin{gathered}
\frac{\partial \pi_{i}^{B T}}{\partial q_{i i}}=a-2 q_{i i}-m q_{j i}-c=0, \\
\frac{\partial \pi_{i}^{B T}}{\partial q_{i j}}=a m-m q_{j j}-2 m^{2} q_{i j}-c=0,
\end{gathered}
$$

which leads to this solution:

$$
q_{i i}^{B T}=\frac{(a-2 c) m+c}{3 m}, \quad q_{i j}^{B T}=\frac{(a+c) m-2 c}{3 m^{2}} .
$$

Comparing the corresponding profits on autarchy, unilateral and bilateral trade, it is clear that $\pi_{i}^{T}>\pi_{i}^{A}, \pi_{i}^{B T}>\pi_{i}^{N T}$ and $\pi_{i}^{A}>\pi_{i}^{B T}$. Therefore:

Proposition 1 Under the static framework trade is dominant strategy for both firms and $\left(\pi_{1}^{B T}, \pi_{2}^{B T}\right)$ is the Nash equilibrium of the game where firms decide to trade or not. This is a prisoner's dilemma game.

Proof. This follows from equilibrium in autarchy and lemmas 1 and 2.

Now, we are interested in welfare comparison across the four cases which is summarized in:

Corollary 1 Under the static framework bilateral trade is Pareto efficient if

$$
h<\frac{k^{2} m^{2}(5 a m+c(17 m-22))}{4(m-2)(c(4+m(-4+7 m))-a m(2+5 m))},
$$

which coincides the equilibrium of the firms' game. Otherwise, social welfare has the most amount in the case of autarchy.

Proof. By plugging $q_{i i}, q_{i j}, q_{j j}$ and $q_{j i}$ into the stationary condition $\dot{Z}=0$, the steady state stock of pollution is obtained which in turn can be plugged into (2) in order to get social welfare amounts in autarchy, unilateral and bilateral trade. Comparing the acquired welfares, we obtain the inequality.

Corollary 2 The less transportation cost is, the more bilateral trade is socially preferable. 
Proof. The right hand side of the inequality (11) is increasing in $m$ which means in order for bilateral trade becomes socially efficient, $h$ can have a larger value when transportation cost decreases. This concludes the proof.

However, trade liberalization would increase firms' output which has two contradictory effects on consumer surplus. Output increase, on the one hand, would directly raise consumer surplus, on the other hand, increases the stock of pollution which in turn reduces consumer surplus. Now, if inequality (11) holds or in the other words $h$ is small enough, pollution increment does not reduce the consumer surplus that much and consumers will benefit from output enlargement. But, we know that most of the time $h$ is not sufficiently small.

\section{The Dynamic Game}

As it is said before, the production of final output creates a cross-boundary negative externality which is accumulated over time and follows the dynamic (1). Now, by introducing a corrective (Pigouvian) tax, in quadratic form, the firms are forced to internalize the negative externality of pollution in a dynamic framework. Therefore, the firm $i$ 's optimization problem is formulated as:

$$
\max _{q_{i}} \Pi_{i} \equiv \int_{0}^{\infty} e^{-r t}\left[p_{i} q_{i i}+p_{j}\left(m q_{i j}\right)-c\left(q_{i i}+q_{i j}\right)-\frac{s}{2} Z^{2}\right] d t
$$

subject to (1) and $Z(0)=Z_{0}$. Parameter $r>0$ is a constant rate of discount common to all firms and parameter $s$ is a policy instrument that policy maker by manipulating it modifies taxation. This taxation is not the same if firms play open-loop or feedback.

In the remainder of this section, the problem is solved for the open-loop equilibrium and feedback equilibrium as well.

\subsection{Open-Loop Solution}

Here we characterize the open-loop equilibria of the three cases, starting with the autarchy which is the simplest one because there is only one supplier in each country.

Proposition 2 At the open-loop Nash equilibrium under autarky, the steady state levels of the price and the individual output are

$$
p_{i}^{O L A}=a-q_{i i}^{O L A}, \quad q_{i i}^{O L A}=\frac{k(a-c)(k+r)}{2(k(k+r)+s)},
$$


where OLA denotes the open-loop equilibrium at autarchy. Such a steady state is saddle point stable.

Proof. The Hamiltonian equation of firm $i$ is:

$$
\begin{aligned}
H_{i}^{A}(t)= & e^{-\rho t}\left\{q_{i i}(t)\left(a-q_{i i}(t)-c\right)-\frac{s}{2} Z^{2}(t)\right. \\
& \left.+\lambda_{i}(t)\left[q_{i i}(t)+q_{j j}(t)-k Z(t)\right]\right\},
\end{aligned}
$$

where $\lambda_{i}(t)=\mu_{i}(t) e^{\rho t}$ and $\mu_{i}(t)$ is the co-state variable associated with $Z(t)$. Consider the first-order condition w.r.t. $q_{i i}(t)$ :

$$
\frac{\partial H_{i}^{A}(t)}{\partial q_{i i}(t)}=a-2 q_{i i}(t)-c+\lambda_{i}(t)=0 .
$$

This yields the optimal open-loop output for the firm $i$ as follows ${ }^{4}$ :

$$
q_{i i}(t)= \begin{cases}\frac{1}{2}\left(a-c+\lambda_{i}(t)\right) & \text { if } a>c-\lambda_{i}(t), \\ 0 & \text { otherwise. }\end{cases}
$$

The adjoint equation for the optimum is

$$
\frac{\partial \lambda_{i}(t)}{\partial t}=r \lambda_{i}(t)-\frac{\partial H_{i}^{A}(t)}{\partial Z(t)}=(k+r) \lambda_{i}(t)+s Z(t),
$$

and the associated transversality condition is

$$
\lim _{t \rightarrow \infty} \mu_{i}(t) \cdot Z(t)=0 .
$$

Differentiating (15), using (16) and symmetry assumption, we obtain

$$
\frac{d q(t)}{d t} \equiv \dot{q}(t)=\frac{1}{2}[(k+r) \lambda(t)+s Z(t)] .
$$

From (14), we know

$$
\lambda(t)=-a+2 q(t)+c .
$$

By substituting this into (17), we have

$$
\dot{q}(t)=-\frac{1}{2}[(k+r)(a-2 q(t)-c)-s Z(t)] .
$$

Therefore, the dynamic system can be rewritten in matrix form as follows:

$$
\left[\begin{array}{c}
\dot{q} \\
\dot{Z}
\end{array}\right]=\left[\begin{array}{cc}
k+r & \frac{s}{2} \\
2 & -k
\end{array}\right]\left[\begin{array}{l}
q \\
Z
\end{array}\right]+\left[\begin{array}{c}
-\frac{1}{2}(k+r)(a-c) \\
0
\end{array}\right] .
$$

\footnotetext{
${ }^{4}$ In the remainder, we consider the positive solution.
} 
Since the determinant of the above two-by-two matrix is negative, the equilibrium point is a saddle, with

$$
p_{i}^{O L A}=a-q_{i i}^{O L A}, \quad q_{i i}^{O L A}=\frac{k(a-c)(k+r)}{2(k(k+r)+s)} .
$$

Proposition 3 At the open-loop Nash equilibrium under unilateral trade, the steady state levels of the price and the individual outputs are

$$
\begin{aligned}
p_{i}^{O L T} & =a-q_{i i}^{O L T}, \quad p_{j}^{O L N T}=a-q_{j j}^{O L N T}-m q_{i j}^{O L T}, \\
q_{i i}^{O L T} & =\frac{3 k m^{2}(a-c)(k+r)+a(m-2)(m-1) s}{6 k m^{2}(k+r)+(4+m(7 m-4)) s}, \\
q_{i j}^{O L T} & =\frac{2 k(c(m-2)+a m)(k+r)+4 a(m-1) s}{6 k m^{2}(k+r)+(4+m(7 m-4)) s}, \\
q_{j j}^{O L N T} & =\frac{2 k m(a m+c-2 c m)(k+r)-a\left(m^{2}+m-2\right) s}{6 k m^{2}(k+r)+(4+m(-4+7 m)) s},
\end{aligned}
$$

where OLT and OLNT denote the open-loop equilibrium in unilateral trade for trading and not trading firms, respectively. Such a steady state is saddle point stable.

Proof. In unilateral trade, only one firm exports. The Hamiltonian for the trading and not trading firms are

$$
\begin{aligned}
H_{i}^{T}(t)= & e^{-\rho t}\left\{\left[p_{i}(t) q_{i i}(t)+p_{j}(t) m q_{i j}-c q_{i}-\frac{s}{2} Z^{2}(t)\right]\right. \\
& \left.+\lambda_{i}(t)\left[q_{i i}(t)+q_{i j}(t)+q_{j j}(t)-k Z(t)\right]\right\}, \\
H_{j}^{N T}(t)= & e^{-\rho t}\left\{\left[p_{j}(t) q_{j j}-c q_{j}-\frac{s}{2} Z^{2}(t)\right]\right. \\
& \left.+\lambda_{j}(t)\left[q_{i i}(t)+q_{i j}(t)+q_{j j}(t)-k Z(t)\right]\right\} .
\end{aligned}
$$

The first-order necessary conditions w.r.t. control variables, adjoint equations and associated transversality conditions for the optimum are

$$
\begin{gathered}
\frac{\partial H_{i}^{T}(t)}{\partial q_{i i}(t)}=a-2 q_{i i}(t)-c+\lambda_{i}(t)=0, \\
\frac{\partial H_{i}^{T}(t)}{\partial q_{i j}(t)}=a m-2 m^{2} q_{i j}(t)-m q_{j j}(t)-c+\lambda_{i}(t)=0, \\
\frac{\partial H_{i}^{N T}(t)}{\partial q_{j j}(t)}=a-2 q_{j j}(t)-m q_{i j}(t)-c+\lambda_{j}(t)=0,
\end{gathered}
$$




$$
\begin{gathered}
\frac{\partial \lambda_{i}(t)}{\partial t}=r \lambda_{i}(t)-\frac{\partial H_{i}^{T}(t)}{\partial Z(t)}=(k+r) \lambda_{i}(t)+s Z(t), \\
\frac{\partial \lambda_{j}(t)}{\partial t}=r \lambda_{j}(t)-\frac{\partial H_{j}^{N T}(t)}{\partial Z(t)}=(k+r) \lambda_{j}(t)+s Z(t), \\
\lim _{t \rightarrow \infty} \mu_{i}(t) . Z(t)=0, \quad \lim _{t \rightarrow \infty} \mu_{j}(t) . Z(t)=0 .
\end{gathered}
$$

Differentiating FOCs w.r.t. time and using adjoint equations we obtain the following control dynamical system:

$$
\left\{\begin{array}{l}
\dot{q}_{i i}(t)=-\frac{1}{2}\left[(k+r)\left(a-2 q_{i i}(t)-c\right)-s Z(t)\right] \\
\dot{q}_{i j}(t)=-\frac{1}{3 m^{2}}\left[(k+r)\left(m\left(a-3 m q_{i j}(t)+c\right)-2 c\right)-s(2-m) Z(t)\right], \\
\dot{q}_{j j}(t)=-\frac{1}{3 m}\left[(k+r)\left(a m-3 m q_{j j}(t)-c(2 m-1)\right)-s(2 m-1) Z(t)\right] .
\end{array}\right.
$$

Solving (28) together with (1), yields the stable steady state equilibrium point in (20).

Proposition 4 At the open-loop Nash equilibrium under bilateral trade, the steady state levels of the price and the individual outputs are

$$
\begin{gathered}
p_{i}^{O L B T}=a-q_{i i}^{O L B T}-m q_{j i}^{O L B T}, \\
q_{i i}^{O L B T}=\frac{k m(a m+c-2 c m)(k+r)+2 a(1-m) s}{3 k m^{2}(k+r)+4(m(m-1)+1) s}, \\
q_{i j}^{O L B T}=\frac{k(c(m-2)+a m)(k+r)+2 a(m-1) s}{3 k m^{2}(k+r)+4(m(m-1)+1) s} .
\end{gathered}
$$

where OLBT denotes the open-loop equilibrium at bilateral trade. Such a steady state is saddle point stable.

Proof. As mentioned before, the two firms and two countries are symmetric. Then, the Hamiltonian function of each firm in bilateral trade is

$$
\begin{aligned}
H_{i}^{B T}(t)= & e^{-\rho t}\left\{\left[p_{i}(t) q_{i i}(t)+p_{j}(t) m q_{i j}-c q_{i}-\frac{s}{2} Z^{2}(t)\right]\right. \\
& \left.+\lambda_{i}(t)\left[q_{i i}(t)+q_{i j}(t)+q_{j j}(t)-q_{j i}(t)-k Z(t)\right]\right\} .
\end{aligned}
$$

Considering the first-order conditions, adjoint equations and associated transversality conditions:

$$
\begin{gathered}
\frac{\partial H_{i}^{B T}(t)}{\partial q_{i i}(t)}=a-2 q_{i i}(t)-m q_{j i}(t)-c+\lambda_{i}(t)=0, \\
\frac{\partial H_{i}^{B T}(t)}{\partial q_{i j}(t)}=m\left(a-2 m q_{i j}(t)-q_{j j}(t)\right)-c+\lambda_{i}(t)=0,
\end{gathered}
$$




$$
\begin{gathered}
\frac{\partial \lambda_{i}(t)}{\partial t}=r \lambda_{i}(t)-\frac{\partial H_{i}^{B T}(t)}{\partial Z(t)}=(k+r) \lambda_{i}(t)+s Z(t), \\
\lim _{t \rightarrow \infty} \mu_{i}(t) \cdot Z(t)=0,
\end{gathered}
$$

yields the dynamics of firm $i$ 's controls:

$$
\left\{\begin{array}{l}
\dot{q}_{i i}(t)=-\frac{1}{3 m}\left[(k+r)\left(a m-3 m q_{i i}(t)-c(2 m-1)\right)-s(2 m-1) Z(t)\right], \\
\dot{q}_{i j}(t)=-\frac{1}{3 m^{2}}\left[(k+r)\left(m\left(a-3 m q_{i j}(t)+c\right)-2 c\right)-s(2-m) Z(t)\right] .
\end{array}\right.
$$

Solving (31) accompanied by the dynamics of firm j's control variables and (1), fully characterizes the stable steady state equilibrium point in (29).

\subsection{Feedback Solution}

Here, we characterize a subgame perfect Cournot equilibrium in Markov strategies where firms employ pollution dependent decision rules when maximizing their discounted profit. Therefore, changes in the stock of pollution stimulate responses, through Pigouvian tax, by all players that are reflected in their quantity choices.

Proposition 5 At the feedback Nash equilibrium under autarky, the steady state levels of the price and the individual output are

$$
p_{i}^{F A}=a-q_{i i}^{F A}, \quad q_{i i}^{F A}=\frac{1}{2}\left(a-c+e^{A} Z+f^{A}\right),
$$

where $F A$ denotes the feedback equilibrium at autarchy and

$$
\begin{aligned}
e^{A} & =\frac{1}{3}\left(2 k+r-\sqrt{(2 k+r)^{2}+6 s}\right), \\
f^{A} & =\frac{2(a-c) e^{A}}{2(k+r)-3 e^{A}} .
\end{aligned}
$$

Proof. The Bellman equation of firm $i$ in autarchy is

$$
\begin{aligned}
r V_{i}(Z(t))= & \max _{q_{i i}(t)}\left\{q_{i i}(t)\left[p_{i}(t)-c\right]-\frac{s}{2} Z^{2}(t)\right. \\
& \left.+\frac{\partial V_{i}(Z(t))}{\partial Z(t)}\left[q_{i i}(t)+q_{j j}(t)-k Z(t)\right]\right\},
\end{aligned}
$$

where $V_{i}(Z(t))$ is the value function of firm $i$. Given the linear quadratic form of the maximand, we assume the quadratic value function:

$$
V_{i}(Z)=\frac{e_{i}}{2} Z^{2}+f_{i} Z+g_{i},
$$


so that

$$
\frac{\partial V_{i}(Z)}{\partial Z}=e_{i} Z+f_{i}
$$

where $e_{i}, f_{i}$ and $g_{i}$ are unknown coefficients and the indication of time is omitted to ease the exposition. Taking the FOC w.r.t. $q_{i i}$ and using (34), we obtain:

$$
q_{i i}^{F A}=\frac{1}{2}\left(a-c+e^{A} Z+f^{A}\right), \quad p_{i}^{F A}=a-q_{i i}^{F A},
$$

where $e^{A}$ and $f^{A}$ can be calculated by using (35) and rewriting (32) as follows:

$$
\beta_{1} Z^{2}+\beta_{2} Z+\beta_{3}=0
$$

where

$$
\begin{aligned}
& \beta_{1}=\frac{1}{4}\left[e\left(3 e^{A}-4 k-2 r\right)-2 s\right] \\
& \beta_{2}=\frac{1}{4}\left[4 e^{A}(a-c)+2 f^{A}\left(3 e^{A}-2(k+r)\right)\right], \\
& \beta_{3}=\frac{1}{4}\left[(a-c)^{2}+f^{A}\left(4(a-c)+3 f^{A}\right)-4 g^{A} r\right] .
\end{aligned}
$$

Equation (36) is satisfied if expressions (37)-(39) are simultaneously zero. This results to the following solution:

$$
\begin{aligned}
e^{A} & =\frac{1}{3}\left(2 k+r-\sqrt{(2 k+r)^{2}+6 s}\right) \\
f^{A} & =\frac{2(a-c) e^{A}}{2(k+r)-3 e^{A}} .
\end{aligned}
$$

Proposition 6 At the feedback Nash equilibrium under unilateral trade, the steady state levels of the prices and the individual outputs are

$$
\begin{gathered}
p_{i}^{F T}=a-q_{i i}^{F T}, \quad p_{j}^{F N T}=a-q_{j j}^{F N T}-m q_{i j}^{F T}, \\
q_{i i}^{F T}=\frac{1}{2}\left(a-c+e^{T} Z^{F T}+f^{T}\right) \\
q_{i j}^{F T}=\frac{(2-m)\left(e^{T} Z^{F T}+f^{T}-c\right)+a m}{3 m^{2}}, \\
q_{j j}^{F N T}=\frac{c+m(a-2 c)+(2 m-1)\left(e^{T} Z^{F T}+f^{T}\right)}{3 m},
\end{gathered}
$$


where FT and FNT denote the feedback equilibrium in unilateral trade for trading and not trading firm and

$$
\begin{aligned}
e^{T} & =\frac{9 m^{2}(2 k+r)-3 \sqrt{9 m^{4}(2 k+r)^{2}+2 m^{2}(16+m(37 m-28)) s}}{16+m(37 m-28)}, \\
f^{T} & =\frac{e^{T}(c(16+m(25 m-22))-a m(11 m+8))}{e^{T}(16+m(37 m-28))-18 m^{2}(k+r)} .
\end{aligned}
$$

Proof. The Bellman equations of trading and not trading firms in unilateral trade $\operatorname{are}^{5}$ :

$$
\begin{aligned}
r V_{i}(Z(t))= & \max _{q_{i}(t)}\left\{\left[p_{i}(t) q_{i i}(t)+p_{j}(t) m q_{i j}-c q_{i}-\frac{s}{2} Z^{2}(t)\right]\right. \\
& \left.+\frac{\partial V_{i}(Z(t))}{\partial Z(t)}\left[q_{i i}(t)+q_{i j}(t)+q_{j j}(t)-k Z(t)\right]\right\}, \\
r V_{j}(Z(t))= & \max _{q_{j}(t)}\left\{\left[p_{j}(t) q_{j j}-c q_{j}-\frac{s}{2} Z^{2}(t)\right]\right. \\
& \left.+\frac{\partial V_{j}(Z(t))}{\partial Z(t)}\left[q_{i i}(t)+q_{i j}(t)+q_{j j}(t)-k Z(t)\right]\right\},
\end{aligned}
$$

with the same value function form that was introduced before. Taking the FOCs w.r.t. controls and using (34), we obtain:

$$
\begin{aligned}
q_{i i}^{F T} & =\frac{1}{2}\left(a-c+e^{T} Z^{F T}+f^{T}\right), \\
q_{i j}^{F T} & =\frac{1}{2 m^{2}}\left(a m-c+e^{T} Z^{F T}+f^{T}-m q_{j j}^{F N T}\right), \\
q_{j j}^{F N T} & =\frac{1}{2}\left(a-c+e^{T} Z^{F T}+f^{T}-m q_{i j}^{F T}\right) .
\end{aligned}
$$

By solving (43) and (44) simultaneously, the amounts of $q_{i j}^{F T}$ and $q_{j j}^{F N T}$ is taken. Using these and rewriting (40) or (41) as (36) and as the same procedure as the previous proof, we can calculate $e^{T}$ and $f^{T}$.

Proposition 7 At the feedback Nash equilibrium under bilateral trade, the steady state levels of the price and the individual outputs are

$$
\begin{gathered}
p_{i}^{F B T}=a-q_{i i}^{F B T}-m q_{j i}^{F B T}, \\
q_{i i}^{F B T}=\frac{c+m(a-2 c)+\left(f^{B T}+e^{B T} z\right)(2 m-1)}{3 m},
\end{gathered}
$$

\footnotetext{
${ }^{5}$ We omit the full calculations but they are available upon request.
} 


$$
\begin{gathered}
q_{i j}^{F B T}=\frac{(2-m)\left(e^{B T} Z^{F B T}+f^{B T}-c\right)+a m}{3 m^{2}}, \\
Z^{F B T}=\frac{2\left(a m(m+1)+2\left(f^{B T}-c\right)(m(m-1)+1)\right)}{3 k m^{2}-4 e^{B T}(m(m-1)+1)},
\end{gathered}
$$

where FBT denotes the feedback equilibrium in bilateral trade and

$$
\begin{aligned}
e^{B T} & =\frac{9 m^{2}(2 k+r)-\sqrt{81 m^{4}(2 k+r)^{2}+36 m^{2}\left(22-28 m+22 m^{2}\right) s}}{2\left(22-28 m+22 m^{2}\right)}, \\
f^{B T} & =\frac{e^{B T}\left(m^{2}(5 a-16 c)+m(5 a+22 c)-16 c\right)}{9 m^{2}(k+r)-e^{B T}\left(22-28 m+22 m^{2}\right)} .
\end{aligned}
$$

Proof. When there is trade between two countries, the Bellman equation of firm $i$ is

$$
\begin{aligned}
r V_{i}(Z(t))= & \max _{q_{i}(t)}\left\{\left[p_{i}(t) q_{i i}(t)+p_{j}(t) m q_{i j}-c q_{i}-\frac{s}{2} Z^{2}(t)\right]\right. \\
& \left.+\frac{\partial V_{i}(Z(t))}{\partial Z(t)}\left[q_{i i}(t)+q_{i j}(t)+q_{j j}(t)-q_{j i}(t)-k Z(t)\right]\right\} .
\end{aligned}
$$

Taking the first order necessary conditions and using the similar procedure with the previous proofs leads to find the Nash equilibrium of the game in bilateral trade ${ }^{6}$.

Remark 8 The parameter $m$ must be belong to $(\underline{m}, 1]$ in which $\underline{m}$ is

$-\frac{2 c}{a+c}$ in the static game,

$-\frac{2 c k(k+r)+2 a s}{k(a+c)(k+r)+2 a s}$ in the open-loop equilibrium,

- the positive root of $k(f-c)(2-m)+a(k m+2 e(1-m))=0$ in the feedback equilibrium where

$(e, f)$ is equal to $\left(e^{T}, f^{T}\right)$ and $\left(e^{B T}, f^{B T}\right)$ for unilateral and bilateral trade, respectively,

otherwise firms do not have an incentive to trade due to high transportation cost. This results from the condition $q_{i j}>0$.

Corollary 3 In the dynamic equilibria, the maximum acceptable transportation cost decreases when $s$ increases and in the limit when s goes to infinity, it must be zero.

Proof. Differentiating $\underline{m}$, illustrated in remark 8 , in the open-loop and the feedback equilibria w.r.t. $s$ we found that $\frac{\partial \underline{m}}{\partial s}>0$. Thus, increasing $s$ leads to increasing the minimum acceptable value of $m$ or in the other word lowering the maximum rate of tranpostation cost by which trade is doable.

\footnotetext{
${ }^{6}$ The full calculations are available upon request.
} 


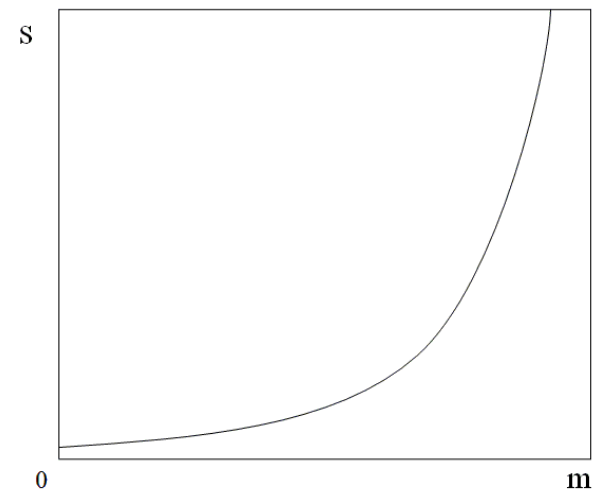

(a)

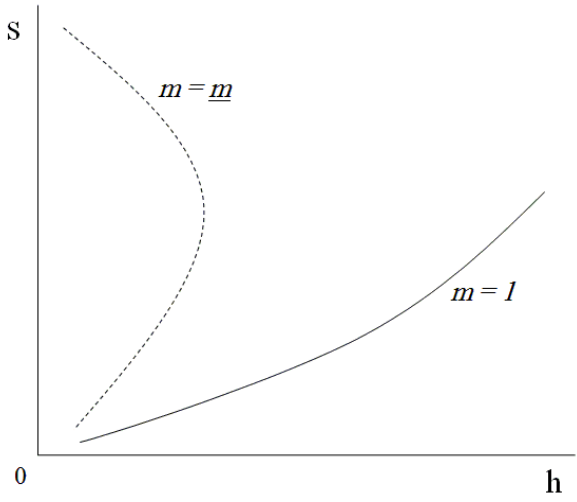

(b)

Figure 2: (a) Profit comparison according to the level of transportation cost and tax rate under the feedback information; (b) welfare comparison according to the level of negative externality and tax rate under the open-loop information

\section{$5 \quad$ Profit and Welfare Assessment}

In this section, by using equilibrium values, we compare firms' profits in autarchy, unilateral and bilateral trade to determine the equilibrium of the game between firms where they decide to trade or not, in the open-loop and in the feedback solutions. In addition, we will look into the case which leads to the efficient level of social welfare.

Because of having too many parameters, comparing the results is difficult. Therefore, we use a numerical analysis to assess the profits and welfares in the three cases for the open-loop and the feedback equilibria, respectively. In our setting, the parameters $a, c, k$ and $r$ are given and in the remainder we assume that they have definite and plausible values of $10,0,0.5$ and 0.05 , respectively.

In figure $2 \mathrm{a}$, the profits of firms in different cases, under open-loop equilibria, is compared according to the amounts of transportation cost and Pigouvian tax. As it can be seen in this figure, the equilibrium of the game illustrated in figure 1 depends on the amounts of $m$ and $s$. In the region below the curve, trade is dominant strategy for both firms which leads to the equilibrium $\left(\pi_{1}^{O L B T}, \pi_{2}^{O L B T}\right)$ and due to the fact that in this region the profit of firms in autarchy is greater than bilateral trade, this game is a prisoner's dilemma. In the region above the curve, the condition of remark 8 is not satisfied. Therefore, non of them choose trade strategy and $\left(\pi_{1}^{O L A}, \pi_{2}^{O L A}\right)$ is the equilibrium of the game.

Figure $2 \mathrm{~b}$ depicts the regions that conditioned on the value of parameters $h, s$ and 


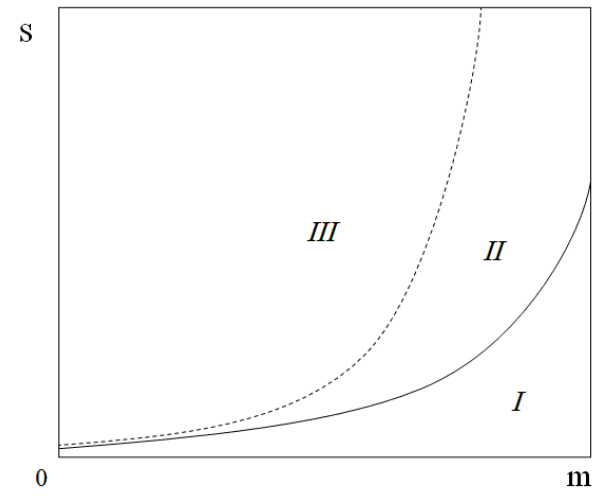

(a)

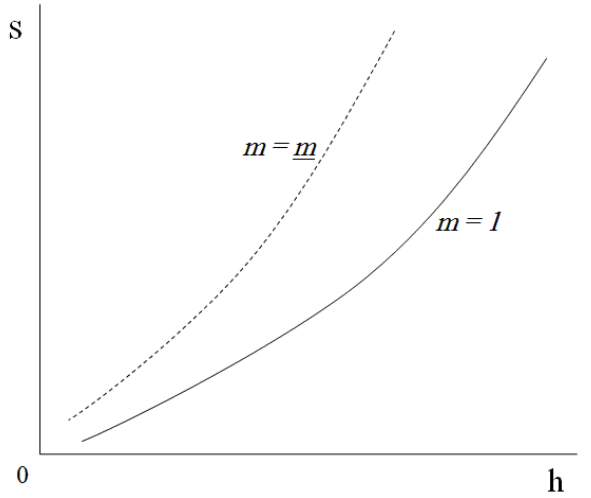

(b)

Figure 3: (a) Profit comparison according to the level of transportation cost and tax rate under the feedback information; (b) welfare comparison according to the level of negative externality and tax rate under the feedback information

$m$ bilateral trade (autarchy) becomes the preferable case from the social welfare point of view. In this figure, for $m=1$, the solid line divides the region of parameters $h$ and $s$ into two areas where in the upper region bilateral trade is socially preferable and in the lower area autarchy. The dashed line does the same but for $m=\underline{m}$. For any other amount of $m$ we have an analogous boderline between the solid and the dash lines. As it can be seen in the figure, when $m$ decreases the area where bilateral trade is socially efficient shrinks. However, depending on the amount of existing $h$, policy maker can determine tax rate in such a way that either bilateral trade or autarchy become socially efficient.

Figure 3a compares the profits of firms in different cases according to the amounts of transportation cost and Pigouvian tax for feedback information. As it can be seen in this figure, in region $I$, where $m$ is close to one and $s$ is not too large, trade is dominant strategy for both firms which leads to the equilibrium $\left(\pi_{1}^{F B T}, \pi_{2}^{F B T}\right)$. In this region the profit of firms in autarchy is greater than bilateral trade, therefore, this equilibrium is not pareto efficient. In region $I I$, there is not any unique equilibrium and firms play a chicken game. If firms play simultaneously, they make a systematic mistake to reach the equilibrium, and if they play sequentially, the problem is who plays first and gains the enormous benefits of the trade. In the last region, III, because of high transportation cost, trade is not possible and autarchy is the equilibrium.

In figure $3 \mathrm{~b}$, it is shown that which one of the three cases (autarchy, unilateral and 
bilateral trade) is socially efficient according to the amounts of negative externality and corrective tax rate. Similar to figure $2 \mathrm{~b}$ the solid line is for $m=1$ and the dashed line is for $m=\underline{m}$. In the region above the curves, bilateral trade is efficient from the social planner point of view. In the other region autarchy is socially efficient. Note that in some situations unilateral trade can be the efficient case socially. It means that if what one country gains is more than what the other looses, over all, they gain. But this makes a huge coordination problem. The problem is that which country accepts not to sell to the other country. In this case, there should be a side payment. Hence, unilateral trade is very hard to sustain.

However, if the social planner makes a deal about taxation, he makes a deal about $s$ as well and this deal is different if he knows firms are playing open-loop equilibrium or feedback equilibrium.

Consequently, if firms play under the open-loop strategies, in order for the socially efficient equilibrium coincides with the market equilibrium, according to the amounts of $h$ and $m$,social planner must determine $s$ in a way that it characterizes a point in the lower (upper) region of figure $2 \mathrm{a}$ and the uper (lower) region in figure $2 \mathrm{~b}$. The most efficient point for the welfare (if it is applicable) takes place on the dividing curves (depended on $m$ ) in figure $2 \mathrm{~b}$.

If firms play under the feedback rule, bilateral trade can be the most preferable case if social planner can determine the tax rate, according to the amounts of $h$ and $m$, in a way that it characterizes a point in region $I$ of figure $3 \mathrm{a}$ and the upper region in figure $3 \mathrm{~b}$. Otherwise, he must choose $s$ such that the equilibrium characterizes a point in region III of figure $3 \mathrm{a}$ and the lower region in figure $3 \mathrm{~b}$ where autarchy is the preferable case.

However, it is not clear to social planners whether firms are playing open-loop or feedback. Considering the figure 2, if social planners assume that firms are playing under open-loop equilibrium and they determine $s$ in order to induce bilateral trade, they may face an unexpected outcome. Because if firms are playing feedback instead of open-loop, autarchy may be welfare improving provided that the point places in the region above the curve in figure $2 \mathrm{~b}$ and below the curve in figure $3 \mathrm{~b}$. Therefore, to avoid this problem policy makers must determine $s$ for any given exogenous pair of $(h, s)$ to satisfy the stricter constraint. 


\section{Concluding Remarks}

In this paper, we have theoretically addressed effects of trade liberalization in a two country world differential polluting oligopoly game. We found out when firms decide to trade or not, if the transportation cost is not too large, under the open-loop information they

play a prisoner's dilemma in which trade is the dominant strategy for both otherwise they play autarchy. In order for trade to be dominant strategy in feedback information, the Pigouvian tax and transportation cost must have relatively lower values. For larger amounts of transportation cost and corrective tax, the equilibrium can be unilateral trade or autarchy.

By comparing social welfares in autarchy, unilateral and bilateral trade, we showed that, depending on the effects of negative externality on consumer and the transportation cost, policy maker can determine the amount of Pigouvian tax so that market equilibrium coincides with socially efficient equilibrium. This taxation is different if firms are playing open-loop equilibrium as compare to the feedback equilibrium.

\section{References}

[1] Antweiler, W., B.R. Copeland and M.S. Taylor (2001). Is free trade good for the environment? American Economic Review, 91, 877-908.

[2] Benchekroun, H. and N.V. Long (1998). Efficiency inducing taxation for polluting oligopolists. Journal of Public Economics, 70, 325-342.

[3] Benchekroun, H. and N.V. Long (2002). On the multiplicity of efficiencyinducing tax rules. Economics Letters, 76, 331-336.

[4] Bergstrom T.C, J.G. Cross and R.C. Porter (1981). Efficiency-Inducing Taxation for a Monopolistically Supplied Depletable Resource, Journal of Public Economics, 15, 23-32.

[5] Chiou, J.-R. and J.-L. Hu (2001). Environmental research joint ventures under emission taxes. Environmental and Resource Economics, 21, 129-46.

[6] Copeland BR, Taylor MS (2003) Trade and the environment: theory and evidence. Princeton University Press, Princeton. 
[7] Damania, D. (1996). Pollution taxes and pollution abatement in an oligopoly supergame. Journal of Environmental Economics and Management, 30, 323-36.

[8] Dockner EJ, N.V. Long (1993) International pollution control: cooperative versus noncooperative strategies.J Environ Econ Manage 25:13-29.

[9] Dockner EJ, Jorgensen S, Long NV, Sorger G (2000). Differential games in economics and management science. Cambridge University Press, Cambridge.

[10] Downing, P.B. and L.J. White (1986). Innovation in pollution control. Journal of Environmental Economics and Management, 8, 225-71.

[11] Dragone, D., L. Lambertini, G. Leitmann and A. Palestini (2010). A Stochastic Optimal Control Model of Pollution Abatement. Nonlinear Dynamics and System Theory, $10(2), 117-124$.

[12] Dragone, D., L. Lambertini, and A. Palestini (2008). The incentive to invest in environmental-friendly technologies: dynamics makes a difference. wp DSE 658-2009.

[13] Dragone, D., L. Lambertini, and A. Palestini (2009). Regulating Environmental Externalities through Public Firms: A Differential Game. Working Paper.

[14] Fujiwara, K., (2009). Why environmentalists resist trade liberalization, Environmental and Resource Economics 44, 71-84.

[15] Karp, L. and J. Livernois (1992). On efficiency-inducing taxation for a non-renewable resource monopolist. Journal of Public Economics, 49, (2), 219-239.

[16] Karp, L. and J. Livernois (1994). Using automatic tax changes to control pollution emissions. Journal of Environmental Economics and Management, 27, 38-48.

[17] Lambertini, L. and A. Mantovani (2008). Collusion Helps Abate Environmental Pollution: A Dynamic Approach. in M. J. Chung, P. Misra and H. Shim (eds), Preprints of the 17th IFAC World Congress (Seoul, Korea, July 6-11 2008), IFAC.

[18] Milliman, S.R. and R. Prince (1989). Firm incentives to promote technological change in pollution control. Journal of Environmental Economics and Management, 17, 24765. 
[19] Rubio SJ, Casino B (2002) A note on cooperative and noncooperative strategies in international pollution control. Resour Energy Econ 24:261-271.

[20] Tsur, Y. and A. Zemel (2002). The regulation of environmental innovations. Journal of Environmental Economics and Management, 44, 242-60.

[21] Tsur, Y. and A. Zemel (2008). Regulating environmental threats. Environmental and Resource Economics, 39, 297-310. 


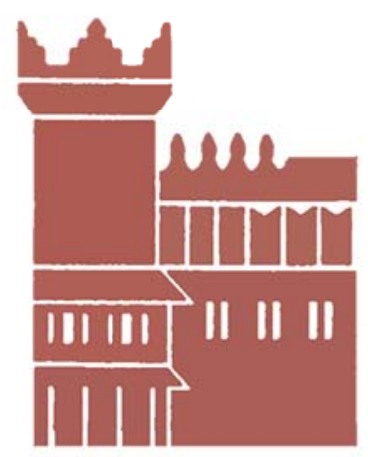

Alma Mater Studiorum - Università di Bologna DEPARTMENT OF ECONOMICS

Strada Maggiore 45

40125 Bologna - Italy

Tel. +39051 2092604

Fax +390512092664

http://www.dse.unibo.it 